\title{
Clinical, sociodemographic and tobacco-use factors associated with smoking cessation rates at three years follow- up, Ankara, Turkey
}

\author{
Bilgen Esmer1, Tijen Sengezer', Funda Aksu², Adem Özkara', Kurtulus Aksu²
}

\begin{abstract}
INTRODUCTION Smoking is a well-known major cause of early preventable mortality and morbidity. Maintenance of smoke-free status is important after a smoking cessation attempt. The present study aims to compare the sociodemographic and clinical characteristics of subjects participating in a smoking-cessation program, according to the duration of smoking cessation.

METHODS A study was conducted in 261 smokers who had attended a smoking cessation clinic in a tertiary hospital, in Ankara, Turkey. The smoking status of the subjects at three years follow-up after participating in the smoking-cessation program was assessed. Sociodemographic, employment, environmental, smokingrelated, health and clinical characteristics of subjects were compared according to the smoking cessation duration.

RESULTS Marital status, having a child, absence of household smoking and lower levels of nicotine dependence were significantly higher in quitters, and anxiety was lower. Parameters that significantly differed between subjects that were and were not abstinent for $>36$ months were marital status $(p<0.001)$, childbearing status $(p=0.007)$, household smoking $(p<0.001)$, age of smoking initiation $(\mathrm{p}=0.02)$, psychiatric illness history $(\mathrm{p}=0.01)$, and number of follow-up visits $(p<0.001)$. The number of follow-up visits at the smoking cessation clinic was an important factor of quitting and maintenance of quit status.

CONCLUSIONS Family and home environment as well as smoking-related and mental health characteristics influenced maintenance of long-term smoking cessation. Characteristics such as sociodemographic, clinical and smoking-related conditions should be considered in smoking cessation interventions. Personalized treatment strategies and follow-up visits at the smoking cessation clinic should be planned for maintenance of smoking cessation.
\end{abstract}

\section{AFFILIATION \\ 1 Ankara Numune Education and Research Hospital, Sinhiye, Ankara, Turkey \\ 2 Ankara Atatürk Chest Diseases and Chest Surgery Education and Research Hospital, Keçiören, Ankara, Turkey}

\section{CORRESPONDENCE TO}

Kurtulus Aksu. Department of Chest Diseases, Health Sciences University Atatürk Chest Diseases and Chest Surgery Education and Research Hospital, Keçiören, Ankara, Turkey. E-mail: kurtulusaksu@yahoo.com

\section{KEYWORDS}

tobacco smoking, cessation, sociodemographic factors

Received: 28 July 2019 Revised: 5 November 2019 Accepted: 7 November 2019

\section{INTRODUCTION}

Smoking is a well-known major cause of early preventable mortality and morbidity. About 6 million people die worldwide every year due to smokingrelated diseases, and it is expected that tobacco will kill as many as 1 billion people this century unless WHO Framework Convention on Tobacco Control is implemented ${ }^{1}$. In 2008 World Health Organization (WHO) Framework Convention on Tobacco Control introduced MPOWER policy package to reverse the tobacco epidemic ${ }^{2}$. Turkey fully implemented the MPOWER package of World Health Organization (WHO) Framework Convention on Tobacco Control. As a means of offering help to quit tobacco, a smoking cessation quitline (Hello 171) was established, which provides consultancy services to those who want to quit smoking and register in smoking cessation clinics such as in the Cancer Early Detection, Screening 
and Training Centers (KETEMs), and in state and university hospitals across Turkey ${ }^{3}$. The present study took place in another establishment also providing smoking cessation services, a tertiary hospital in Ankara.

To develop and implement more effective tobacco control measures, the assessment of the association between sociodemographic factors and smoking cessation is crucial. Maintenance of smoke-free status is as important as smoking cessation itself in preventing smoking-related morbidity and mortality.

The aim of this study was to investigate the sociodemographic, clinical and smoking-related factors that may be associated with long-term abstinence ( $>36$ months smoking cessation) in subjects attending a specialized smoking-cessation clinic.

\section{METHODS}

\section{Recruitment}

The study was conducted in adults aged 18-65 years who were either referred, because of their comorbid conditions, or who applied voluntarily, to a smoking cessation clinic of tertiary care services in Ankara, Turkey, between January and December 2011. Subjects were not included in the study if their sociodemographic, employment, environmental, health characteristics, smoking-related and clinical data were not completely available in the hospital records. The study sample did not include patients with major psychiatric affects such as psychoses, as they were followed in a different clinic for psychiatric disorders. Subjects who were willing to participate in the study and gave information about their smoking status three years after participating in the smoking cessation program were involved in the study.

Hospital files of 530 subjects could be reached from a total of 840 subjects followed in the smokingcessation clinic between the specified dates. These subjects were contacted by phone and 261 agreed to volunteer for the study. The study was approved by Ankara Numune Training and Research Hospital Ethics Committee (297/2014).

\section{Assessment of sociodemographic, employment, environmental, smoking-related, health and clinical characteristics}

The subjects' sociodemographic data (age, gender, education level, marital and childbearing status), employment status, household smoking, smokingrelated parameters (age of smoking initiation and cumulative amount of smoking), health characteristics (psychiatric illness history, comorbid systemic illness) and clinical characteristics (level of nicotine dependence, level anxiety and clinical assessment of mood) were obtained from the patients' files. Subjects had been prescribed varenicline, bupropion, or bupropion together with nicotine replacement treatment according to their clinical assessment in the smoking-cessation program. None of the subjects received only nicotine-replacement therapy. Medications used by the patients within the smokingcessation program were free-of-charge. The choice of smoking cessation treatment and clinical follow-up regarding frequency of visits, were also noted from the hospital files.

The age of smoking initiation was evaluated in three age groups: $<16,16-22$, and $>22$ years. The cumulative amount of smoking was calculated as pack-years by multiplying the number of years of smoking by the number of packs smoked per day. Level of nicotine dependence was assessed with the Fagerström Test for Nicotine Dependence (FTND): 'low or very low' (0-4), 'moderate' (5), and 'high or very high' (6-10), on a 10-point scale. Beck's Depression Inventory (BDI-21) and Beck's Anxiety Inventory (BAI) were used to assess subjects' emotional states. The subjects' level of depression was categorized based on their BDI-21 score: 'absence of or mild mood disturbance' $(\leq 16)$, 'borderline clinical or moderate depression' (17$30)$, and 'severe or very severe depression' $(\geq 31)$. The subjects' level of anxiety was graded according to their BAI score: 'minimal' (0-7), 'mild' (8-15), 'moderate' (16-25), and 'severe' (26-63).

\section{Assessment of the smoking status of subjects}

The smoking status of the subjects at three years follow-up after participating in the smoking-cessation program was assessed through telephone interview. Smokers who participated in the smoking-cessation program in 2011 were called by phone to assess their smoking status three years after participating in the program. Subjects were questioned about their smoking status based on three parameters: 1) if they had quit for at least three months after participating in the program; 2) whether they restarted smoking after 
successfully quitting for at least three months and if so, the duration they maintained their quit status; and 3 ) their smoking status three years after participating in the program. Accordingly, subjects were divided into five groups depending on the months they remained abstinent after admission to the program: $<3,3-6,6-12,12-36$, and $>36$ months.

\section{Outcome measures}

Sociodemographic, employment, household smoking, smoking related, health and clinical characteristics of subjects who never quit smoking and subjects having quit for three months or more were compared to assess the factors that contributed to the success of a quit attempt. Subject characteristics were compared to determine which factors may have affected the duration of smoking abstinence after participating in the smoking-cessation program, these included: sociodemographic, employment, environmental, smoking-related, health and clinical characteristics of subjects who refrained from smoking for $<3,3-6$, $6-12,12-36$, and $>36$ months. Subsequently, in order to determine the factors that affect long-term smoking cessation, the same analyses were performed between subjects abstinent and not abstinent for $>36$ months.

\section{Statistical analysis}

Continuous variables (age, age of smoking initiation, cumulative amount of smoking, and number of follow-up visits) were grouped into categories and were transformed into categorical variables. All variables were expressed as numbers and percentages. For comparison of subjects with different smoking cessation periods, chi-squared test or Fisher's exact test was used. All statistical tests were two-sided and a $p$-value $<0.05$ was considered statistically significant. The analyses were performed using SPSS (Statistical Package for the Social Sciences) ${ }^{\circledR}$ version 22.

\section{RESULTS}

Sociodemographic, employment, household smoking, smoking-related and health characteristics of the study subjects are presented in. Assessment of the clinical characteristics of the subjects is summarized in Table 2.

Among study subjects, pharmaceutical intervention was planned with varenicline in 150 (57.5\%), bupropion in $85(32.6 \%)$ or bupropion
Table 1. Sociodemographic, employment, environmental, smoking related and health characteristics of the study population $(\mathrm{N}=261)$

\begin{tabular}{|c|c|}
\hline Sociodemographic & n $(\%)$ \\
\hline \multicolumn{2}{|l|}{ Age (years) } \\
\hline $18-24$ & $10(3.8)$ \\
\hline $25-34$ & $79(30.3)$ \\
\hline $35-44$ & $104(39.8)$ \\
\hline $45-54$ & $53(20.3)$ \\
\hline $55-65$ & $15(5.7)$ \\
\hline \multicolumn{2}{|l|}{ Gender } \\
\hline Male & $170(65.1)$ \\
\hline Female & $91(34.9)$ \\
\hline \multicolumn{2}{|l|}{ Educational level } \\
\hline Primary education & $74(28.4)$ \\
\hline Secondary education & $93(35.6)$ \\
\hline University & $94(36.0)$ \\
\hline \multicolumn{2}{|l|}{ Marital status } \\
\hline Married & $208(79.7)$ \\
\hline Single & $37(14.2)$ \\
\hline Divorced/widowed & $16(6.1)$ \\
\hline \multicolumn{2}{|l|}{ Child-bearing status } \\
\hline Yes & $210(80.5)$ \\
\hline No & $51(19.5)$ \\
\hline \multicolumn{2}{|l|}{ Employment } \\
\hline Student & $5(1.9)$ \\
\hline Employed & $194(74.3)$ \\
\hline Unemployed/retired & $62(23.8)$ \\
\hline \multicolumn{2}{|l|}{ Environmental } \\
\hline \multicolumn{2}{|l|}{ Household smoking } \\
\hline Yes & $117(44.8)$ \\
\hline No & $144(55.2)$ \\
\hline \multicolumn{2}{|l|}{ Smoking-related } \\
\hline \multicolumn{2}{|c|}{ Age of smoking initiation (years) } \\
\hline$<16$ & $76(29.1)$ \\
\hline $16-22$ & $165(63.2)$ \\
\hline$>22$ & $20(7.7)$ \\
\hline \multicolumn{2}{|c|}{ Cumulative amount of smoking (pack-years) } \\
\hline$<10$ & $29(11.1)$ \\
\hline $10-20$ & $78(29.9)$ \\
\hline $20-30$ & $78(29.9)$ \\
\hline$>30$ & $76(29.1)$ \\
\hline \multicolumn{2}{|l|}{ Health } \\
\hline \multicolumn{2}{|c|}{ Psychiatric illness history } \\
\hline Yes & $75(28.7)$ \\
\hline No & $186(71.3)$ \\
\hline \multicolumn{2}{|c|}{ Comorbid systemic illness } \\
\hline Yes & $112(42.9)$ \\
\hline No & $149(57.1)$ \\
\hline
\end{tabular}


Table 2. Clinical characteristics of the study population $(\mathrm{N}=261)$

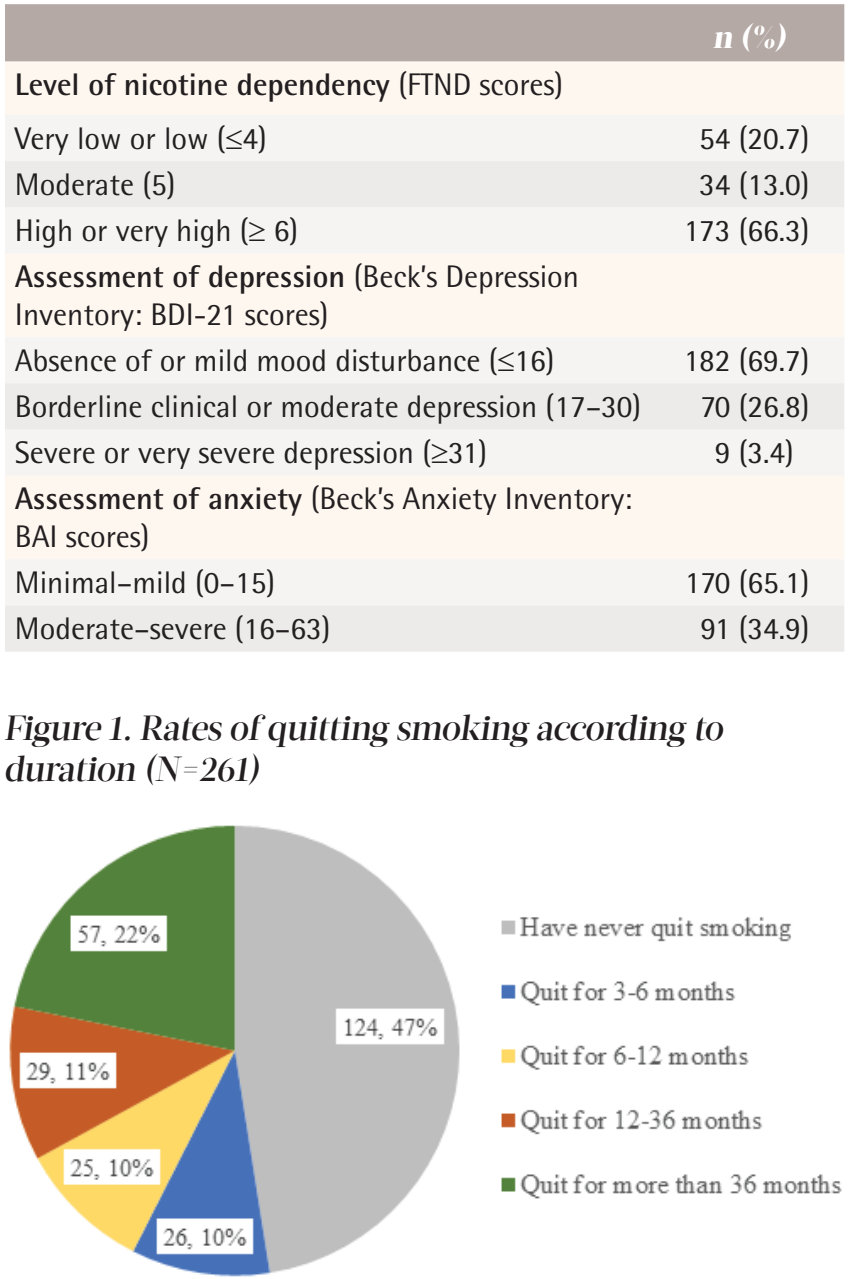

together with nicotine replacement treatment in $26(10.0 \%)$ subjects, according to their clinical assessment. Upon admission to the smoking cessation program, follow-up visits were scheduled as 4-6 visits for the first 3 months, two visits on the 6 th and 12 th month, and additional visits any time according to the patient's needs.

Of 261 study subjects, 124 (47.5\%) had never quit smoking, 26 subjects (10.0\%) had stopped smoking for 3-6 months, 25 subjects (9.6\%) had stopped smoking for 6-12 months, 29 subjects (11.1\%) had stopped smoking for 12-36 months, and 57 subjects $(21.8 \%)$ had stopped smoking for more than 3 years (Figure 1).

Parameters that significantly differed between the subjects that quit and not quit smoking for at least 3 months were marital status $(p=0.007)$,
Table 3. Parameters significantly different between subjects who never quit smoking and subjects having quit for at least 3 months

\begin{tabular}{|c|c|c|c|}
\hline Parameter & $\begin{array}{c}\text { Abstinent } \\
\begin{array}{c}(\mathrm{N}=137) \\
\text { n }(\%)\end{array}\end{array}$ & $\begin{array}{l}\text { Vever } \\
\text { abstinent } \\
(\mathrm{N}=121) \\
\text { n }(\%)\end{array}$ & $p$ \\
\hline Marital status & & & 0.007 \\
\hline Married $(n=208)$ & $118(86.1)$ & $90(72.6)$ & \\
\hline Single/divorced $(n=53)$ & $19(13.9)$ & $34(27.5)$ & \\
\hline Child-bearing status & & & 0.03 \\
\hline Yes $(n=210)$ & $117(85.4)$ & $93(75.0)$ & \\
\hline No $(n=51)$ & $20(14.6)$ & $31(25.0)$ & \\
\hline Household smoking & & & 0.001 \\
\hline Yes $(n=117)$ & $48(35.0)$ & $69(55.6)$ & \\
\hline No $(n=144)$ & $89(65.0)$ & $55(44.4)$ & \\
\hline $\begin{array}{l}\text { Level of nicotine dependency } \\
\text { (FTND scores) }\end{array}$ & & & 0.03 \\
\hline Very low or low $(\leq 4)(n=54)$ & $31(22.6)$ & $23(18.5)$ & \\
\hline Moderate (5) $(n=34)$ & $24(17.5)$ & $10(8.1)$ & \\
\hline High or very high $(\geq 6)(n=173)$ & $82(59.9)$ & $91(73.4)$ & \\
\hline $\begin{array}{l}\text { Level of anxiety (Beck's Anxiety } \\
\text { Inventory scores) }\end{array}$ & & & 0.04 \\
\hline Minimal-mild (0-15) $(n=170)$ & 97 (70.8) & $73(58.9)$ & \\
\hline $\begin{array}{l}\text { Moderate-severe }(16-63) \\
(n=91)\end{array}$ & $40(29.2)$ & $51(41.1)$ & \\
\hline $\begin{array}{l}\text { Number of follow-up visits } \\
\text { attended }\end{array}$ & & & $<0.001$ \\
\hline $0(n=106)$ & $26(19.0)$ & $80(64.5)$ & \\
\hline $1(n=68)$ & $42(30.7)$ & $26(21.0)$ & \\
\hline $2(n=41)$ & $31(22.6)$ & $10(8.1)$ & \\
\hline$\geq 3(n=46)$ & $38(27.7)$ & $8(6.5)$ & \\
\hline
\end{tabular}

Chi-squared test or Fisher's exact test was used in the analyses.

childbearing status $(\mathrm{p}=0.03)$, household smoking $(p=0.001)$, FTND score $(p=0.03)$, level of anxiety $(\mathrm{p}=0.04)$, and number of follow-up visits within the smoking-cessation program $(\mathrm{p}<0.001)$. The rates of being single, not having children, presence of other smokers in the household, high or very high nicotine dependency, and moderate-severe anxiety, were higher among subjects who never quit smoking (Table 3).

Comparison of sociodemographic, employment, household smoking, smoking-related, health and clinical characteristics between subjects who refrained from smoking for $<3,3-6,6-12,12-36$ and $>36$ months, revealed that marital status $(p=0.002)$, childbearing status $(\mathrm{p}=0.049)$, household smoking $(p=0.001)$, educational level $(p=0.02), \operatorname{mood}$ encountered by BDI-21 $(p=0.02)$ and number 
Table 4. Parameters significantly different between subjects grouped according to duration (months) of smoking abstinence

\begin{tabular}{|c|c|c|c|c|c|c|}
\hline Parameters & $\begin{array}{c}3(\mathrm{n}-121) \\
n(\%)\end{array}$ & $\begin{array}{c}36(n-26) \\
n(\%)\end{array}$ & $\begin{array}{c}6-12(n-25) \\
n(\%)\end{array}$ & $\begin{array}{c}1236(\mathrm{n}-29) \\
n(\%)\end{array}$ & $\begin{array}{c}36(n-57) \\
n(\%)\end{array}$ & $p$ \\
\hline Marital status & & & & & & 0.002 \\
\hline Married & $90(72.6)$ & $19(73.1)$ & $21(84.0)$ & $22(75.9)$ & $56(98.2)$ & \\
\hline Single/divorced & $34(27.5)$ & $7(26.9)$ & $4(16.0)$ & $7(24.1)$ & $1(1.8)$ & \\
\hline Child-bearing status & & & & & & 0.049 \\
\hline Yes & $93(75.0)$ & $20(76.9)$ & $22(88.0)$ & $22(75.9)$ & $53(93.0)$ & \\
\hline No & $31(25.0)$ & $6(23.1)$ & $3(12.0)$ & $7(24.1)$ & $4(7.0)$ & \\
\hline Household smoking & & & & & & 0.001 \\
\hline Yes & $69(55.6)$ & $14(53.8)$ & $10(40.0)$ & $10(34.5)$ & $14(24.6)$ & \\
\hline No & $55(44.4)$ & $12(46.2)$ & $15(60.0)$ & $19(65.5)$ & $43(75.4)$ & \\
\hline Educational level & & & & & & 0.02 \\
\hline Primary education & $36(29.0)$ & $8(30.8)$ & $12(48.0)$ & $3(10.3)$ & $15(26.3)$ & \\
\hline Secondary education & $50(40.3)$ & $8(30.8)$ & $6(24.0)$ & $7(24.1)$ & $22(38.6)$ & \\
\hline University & $38(30.6)$ & $10(38.5)$ & $7(28.0)$ & $19(65.5)$ & $20(35.1)$ & \\
\hline Clinical assessment of mood & & & & & & 0.02 \\
\hline Absence of or mild mood disturbance (BDI-21 $\leq 16)$ & $83(66.9)$ & $12(46.2)$ & $18(72.0)$ & $23(79.3)$ & $46(80.7)$ & \\
\hline 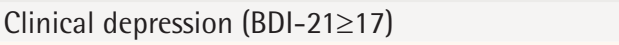 & $41(33.1)$ & $14(53.8)$ & $7(28.0)$ & $6(20.7)$ & $11(19.3)$ & \\
\hline Number of follow-up visits subjects attended & & & & & & $<0.001$ \\
\hline 0 & $80(64.5)$ & $10(38.5)$ & $4(16.0)$ & $6(20.7)$ & $6(10.5)$ & \\
\hline 1 & $26(21.0)$ & $7(26.9)$ & $10(40.0)$ & $7(24.1)$ & $18(31.6)$ & \\
\hline 2 & $10(8.1)$ & $8(30.8)$ & $6(24.0)$ & 8 (27.6) & $9(15.8)$ & \\
\hline$\geq 3$ & $8(6.4)$ & $1(3.8)$ & $5(20.0)$ & $8(27.6)$ & $24(42.1)$ & \\
\hline
\end{tabular}

Chi-squared test or Fisher's exact test was used in the analyses.

Table 5. Parameters significantly different between subjects having and not having quit for more than 36 months

\begin{tabular}{|c|c|c|c|}
\hline Parameter & $\begin{array}{c}\text { Abstinent } \\
\begin{array}{c}(\mathbf{N}=57) \\
\text { n }(\%)\end{array}\end{array}$ & $\begin{array}{l}\text { Not } \\
\text { abstinent } \\
(\mathrm{N} 201) \\
\text { n }(\%)\end{array}$ & p \\
\hline Marital status & & & $<0.001$ \\
\hline Married & $56(98.2)$ & $152(74.5)$ & \\
\hline Single/divorced & $1(1.8)$ & $52(25.5)$ & \\
\hline Child-bearing status & & & 0.007 \\
\hline Yes & $53(93.0)$ & $157(77.0)$ & \\
\hline No & $4(7.0)$ & $47(23.0)$ & \\
\hline Household smoking & & & $<0.001$ \\
\hline Yes & $14(24.6)$ & $103(50.5)$ & \\
\hline No & $43(75.4)$ & $101(49.5)$ & \\
\hline Age of smoking initiation & & & 0.02 \\
\hline$<16$ & $10(17.5)$ & $66(32.4)$ & \\
\hline $16-22$ & $39(68.4)$ & $126(61.8)$ & \\
\hline$>22$ years & $8(14.0)$ & $12(5.9)$ & \\
\hline Psychiatric illness history & & & 0.01 \\
\hline Yes & $9(15.8)$ & 66 (32.4) & \\
\hline No & $48(84.2)$ & $138(67.6)$ & \\
\hline $\begin{array}{l}\text { Number of scheduled control } \\
\text { visits attended }\end{array}$ & & & $<0.001$ \\
\hline 0 & $6(10.5)$ & $100(49.0)$ & \\
\hline 1 & $18(31.6)$ & $50(24.5)$ & \\
\hline 2 & $9(15.8)$ & $32(15.7)$ & \\
\hline$\geq 3$ & $24(42.1)$ & $22(10.8)$ & \\
\hline
\end{tabular}

Chi-squared test or Fisher's exact test was used in the analyses. of follow-up visits $(\mathrm{p}<0.001)$, were significantly different. Whereas age $(p=0.27)$, gender $(p=0.87)$, occupation $(p=0.46)$, level of nicotine dependency assessed by Fagerström Test for Nicotine Dependency $(p=0.07)$, level of anxiety assessed by BAI $(p=0.16)$, age of smoking initiation $(p=0.20)$, cumulative amount of smoking $(\mathrm{p}=0.50)$, presence of comorbid illness $(p=0.80)$, psychiatric illness history $(p=0.10)$, and medications used for smoking cessation $(p=0.61)$, were not significantly different between the five groups (Table 4).

Parameters that significantly differed between subjects who were abstinent and not abstinent for $>36$ months were marital status $(p<0.001)$, childbearing status $(\mathrm{p}=0.007)$, household smoking $(p<0.001)$, age of smoking initiation $(p=0.02)$, psychiatric illness history $(\mathrm{p}=0.01)$, and number of follow-up visits $(\mathrm{p}<0.001)$ (Table 5).

\section{DISCUSSION}

The present study is important in revealing factors influencing smoking cessation and maintaining quit status in smokers who voluntarily participated in a smoking-cessation program. Frequency of being married, having a child, and absence of household 
smoking, were significantly higher both in subjects who were able to quit smoking for at least 3 months and in those who were able to maintain their quit status for more than 3 years. Also, low or moderate level of nicotine dependence and minimal-mild levels of anxiety were significantly more frequent in subjects who were able to quit smoking for at least 3 months. Parameters significantly different between subjects having and not having quit for more than 3 years were age of smoking initiation and psychiatric disorder history.

Smoking cessation interventions are important components of MPOWER policy as means of offering help to smokers to quit tobacco use. Smoking cessation rates are reported as $16-22 \%$ with behavioral therapy ${ }^{4}, 15-25 \%$ with nicotine replacement treatment ${ }^{5,6}, 28.8-44.2 \%$ with bupropion $^{7}$, and $23-29.7 \%$ with varenicline ${ }^{8}$. The rate of success in quitting cigarette smoking after attempting a smoking-cessation program also depends on demographic factors such as age, level of education, marital status, household smoking, and work conditions ${ }^{9}$. In 2011, the Turkish Ministry of Health supported a smoking-cessation treatment program that provided coverage of medication expenditures for treatment of nicotine dependence for smokers who were willing to quit. The smoking cessation success rate of this program was reported to be $28.0 \%$ at follow-up at one year. Smoking cessation rates were higher in the elderly, females, participants with lower Fagerström scores, those with comorbidities such as hypertension, diabetes mellitus, coronary artery disease and cerebrovascular events, and if medication for nicotine dependence was used for more than 3 months. Significant factors found to be related to the maintenance of smoking cessation for 12 months were: longer duration of medical intervention for smoking cessation, absence of COPD and absence of cancer, in the same study ${ }^{10}$. Differently from the report published by Çelik et al. ${ }^{10}$, which included subjects who were admitted to primary, secondary and tertiary health-care facilities in Turkey, the subjects in the present study were followed in a single smoking cessation clinic in a tertiary hospital in Ankara. Moreover, the smoking cessation rates were evaluated at follow-up at 3 years.

For the maintenance of tobacco control interventions regarding smoking-related mortality and morbidity, the long-term cessation in the population of smokers is at least as important as successful quitting. Approximately 65 per cent of all quitters relapsed in the first 3 months, with 10 per cent more relapsing from 3 to 6 months after quitting, and an additional 3 per cent relapsing between 6 months and one year following a quit attempt ${ }^{11}$.

Determining the factors that influence longterm smoking cessation is important since it may enable to identify subjects who are at high risk of failure to maintain quit status, and to design individualized treatment strategies and follow-up. Previous studies have reported older age, being married, high educational level, low levels of daily cigarette consumption, initiation of smoking after the age of 20 years, and absence of other smokers in the household as other factors related to higher quit rates $^{12-14}$, while older age, high educational level, low prior tobacco consumption, high social status and absence of other smokers in household were predictors of long-term smoking cessation ${ }^{15,16}$.

This study reveals that family and housing circumstances, as well as smoking-related and mental health characteristics of subjects, influence maintenance of smoking cessation. Maintenance of quit status for more than 36 months was as low as $1.8 \%$ among subjects who were single or divorced, and $7 \%$ among subjects without children. Smoking cessation rate over 36 months was found to decrease to about half in the presence of other smokers in the household. Marital status, childbearing status and household smoking were factors affecting successful quit after a cessation attempt and maintenance of abstinence. Although some study results reveal that male gender is related to higher quit rates and is a predictor of long-term smoking cessation, gender difference is not related to effectiveness of smokingcessation treatment in real-world assessments ${ }^{17}$. In the present study gender was not found to be related to smoking cessation rate over 36 months following a smoking-cessation program.

Clinical evaluation of mood in subjects who attended the smoking-cessation program is critical because the presence of depressive symptoms assessed with BDI-21 are related to lower rates of abstinence. According to study results, subjects with clinical depression (BDI-21 $\geq 17$ ) had lower rates of 
maintenance of quit status. Moreover, none of the subjects with severe and extreme depression (BDI21 score $\geq 31$ ) had refrained from smoking for more than 12 months. Similarly, age of smoking initiation is also a significant factor that should be considered in follow-up of subjects in smoking-cessation programs. Smoking cessation rate for 36 months was higher among subjects who started smoking after 22 years of age and lower in subjects who started smoking before 16 years of age.

Psychiatric illness history was another parameter important for abstinence. In the present study, the rate of refraining from smoking for more than 36 months in subjects with psychiatric illness history was half that of those without a history of illness. Smoking cessation interventions in smokers with psychiatric disorders is a public health problem. Smoking patterns and smoking cessation interventions have some unique features in these subjects $^{18}$. Smoking is even more prevalent among people with psychiatric illness and they suffer greater morbidity and mortality from smoking ${ }^{19}$. Smoking prevalence is twice as high among depressive subjects ${ }^{20}$. In a population-based study, smoking prevalence ranged from $34.3 \%$ to $59.1 \%$ in adults with mental illness or serious psychological distress compared with $18.3 \%$ in adults with no such illness ${ }^{21}$. The neurobiological association between smoking behavior and psychological disorders has also been shown ${ }^{22}$. People with psychiatric disorders are more nicotine-dependent and quit smoking at lower rates compared to the general population. Successful smoking cessation rates were reported to be lower in individuals with mental illnesses compared to those without this condition, 26-45\% versus $54 \%$, respectively ${ }^{21}$.

The number of follow-up visits subjects attended within the smoking-cessation program was significantly different between subjects who were or were not able to quit smoking for at least three months, and between subjects with different smoking cessation periods. This finding highlights the importance of follow-up visits and close followup in smoking cessation interventions. Accordingly, follow-up visits should be encouraged, especially in subjects who are not likely to refrain from smoking after quitting. In order to maintain quit status, follow-up should be extended to 3 years or more according to clinical evaluations based on whether subjects: are single, have no children, have other smokers in the household, started smoking at an early age, have a history of psychiatric illness, have high BDI-21 scores.

\section{Limitations and strengths}

In this study, information on subjects' smoking status and their smoking cessation duration relied on self-reports to determine smoking status instead of verification by measurement of exhaled CO levels. Since the number of follow-up visits subjects attended within the smoking-cessation program was significantly different between subjects with different smoking cessation duration, it is concluded that follow-up visits help in maintaining smoking cessation. However, this finding might be because those continuing cessation will come for follow-up visits, while the others drop out. Also, all subjects that were followed in the smoking-cessation clinic between the specified dates were not included in the study due to missing data in the hospital files of some subjects and that some of the patients refused to participate in the study. The study sample did not include patients with major psychiatric affects such as psychoses as they were followed in a different clinic for psychiatric disorders. The major strength of the present study is that it evaluates smoking cessation success over 3 years.

\section{CONCLUSIONS}

This study showed that family and housing circumstances, as well as smoking-related and mental health characteristics of subjects, influence maintenance of smoking cessation. The study presents long-term smoking cessation rates in smokers who are self-motivated to quit and highlights the influence of clinical and demographic features on the continuation of smoking abstinence, from a follow-up at 3 years. Determination of demographical and clinical factors influencing long-term smoking cessation rates may enable to identify subjects who have high-risk of failure to maintain quit status, and to individualize treatment strategies and follow-up.

\section{REFERENCES}

1. World Health Organization. WHO Report on the Global Tobacco Epidemic: Enforcing bans on tobacco advertising, 
promotion and sponsorship. Geneva, Switzerland: World Health Organization; 2013. https://apps.who.int/iris/ bitstream/handle/10665/85380/9789241505871_eng.pdf; jsessionid=50E67 B 1173550 D09BDCD37D24DD 780E6?sequence=1. Accessed August 24, 2016.

2. World Heath Organization. MPower: a policy package to reverse the tobacco epidemic. Geneva, Switzerland: World Health Organization; 2008. http://www.who.int/ tobacco/mpower/mpower_english.pdf. Accessed January 18, 2018.

3. Calikoglu EO, Koycegiz E. Tobacco Control Policies in Turkey in Terms of MPOWER. Eurasian J Med. 2019;51(1):80-84. doi:10.5152/eurasianjmed.2018.18009

4. Lando HA, McGovern PG, Barrios FX, Etringer BD. Comparative evaluation of American Cancer Society and American Lung Association smoking cessation clinics. Am J Public Health. 1990;80(5):554-559. doi:10.2105/ajph.80.5.554

5. Renaud JM, Halpern MT. Clinical management of smoking cessation: patient factors affecting a rewardbased approach. Patient Prefer Adherence. 2010;4:441450. doi:10.2147/PPA.S8913

6. Stead LF, Perera R, Bullen C, Mant D, Lancaster T. Nicotine replacement therapy for smoking cessation. Cochrane Database Syst Rev. 2008;(1):CD000146. doi:10.1002/14651858

7. Hurt RD, Sachs DP, Glover ED, et al. A comparison of sustained-release bupropion and placebo for smoking cessation. N Engl J Med. 1997 ;337(17):1195-1202. doi:10.1056/NEJM199710233371703

8. Garrison GD, Dugan SE. Varenicline: a first-line treatment option for smoking cessation. Clin Ther. 2009;31(3):463491. doi:10.1016/j.clinthera.2009.03.021

9. Lee GW, Kahende J. Factors associated with successful smoking cessation in the United States, 2000. Am J Public Health. 2007;97(8):1503-1509. doi:10.2105/AJPH.2005.083527

10. Çelik İ, Yüce D, Hayran M, et al. Nationwide Smoking Cessation Treatment Support ProgramTurkey project. Health Policy. 2015;119(1):50-56. doi:10.1016/j.healthpol.2014.11.017

11. Burns DM, Anderson CM, Johnson M, Major JM, Biener L, Vaughn J, Shanks T. Cessation and Cessation Measures among Adult Daily Smokers: National and State-Specific Data. In: Population Based Smoking Cessation: Proceedings of a Conference on What Works to Influence Cessation in the General Population. Smoking and Tobacco Control Monograph No 12. Washington, DC: US Department of Health and Human Services, Public Health Service, National Institutes of Health, National Cancer Institute; 2000. https://cancercontrol.cancer. gov/brp/tcrb/monographs/12/entire_monograph-12. pdf. Accessed July 5, 2019.

12. Monsó E, Campbell J, Tønnesen P, Gustavsson G, Morera J. Sociodemographic predictors of success in smoking intervention. Tob Control. 2001;10(2):165-169. doi:10.1136/tc.10.2.165

13. Hymowitz N, Cummings KM, Hyland A, Lynn WR, Pechacek TF, Hartwell TD. Predictors of smoking cessation in a cohort of adult smokers followed for five years. Tob Control. 1997;6(Suppl 2):S57-S62. doi:10.1136/tc.6.suppl_2.s57

14. Lee $\mathrm{CW}$, Kahende J. Factors associated with successful smoking cessation in the United States, 2000. Am J Public Health. 2007;97(8):1503-1509. doi:10.2105/AJPH.2005.083527

15. Kaleta D, Korytkowski P, Makowiec-Dąbrowska T, Usidame B, Bąk-Romaniszyn L, Fronczak A. Predictors of long-term smoking cessation: results from the global adult tobacco survey in Poland (2009-2010). BMC Public Health. 2012;12:1020. doi:10.1186/1471-2458-12-1020

16. Osler M, Prescott E. Psychosocial, behavioural, and health determinants of successful smoking cessation: a longitudinal study of Danish adults. Tob Control. 1998;7(3):262-267. doi:10.1136/tc.7.3.262

17. Caponnetto P, Polosa R. Common predictors of smoking cessation in clinical practice. Respir Med. 2008;102(8):1182-1192. doi:10.1016/j.rmed.2008.02.017

18. Keizer I, Gex-Fabry M, Croquette P, Humair J, Khan AN. Tobacco craving and withdrawal symptoms in psychiatric patients during a motivational enhancement intervention based on a 26-hour smoking abstinence period. Tob Prev Cessation. 2019;5(June):1-14. doi:10.18332/tpc/109785

19. Colton CW, Manderscheid RW. Congruencies in increased mortality rates, years of potential life lost, and causes of death among public mental health clients in eight states. Prev Chronic Dis. 2006;3(2):A42. PMID:16539783.

20. Lasser K, Boyd JW, Woolhandler S, Himmelstein DU, McCormick D, Bor DH. Smoking and mental illness: A population-based prevalence study. JAMA. 2000;284(20):2606-2610. doi:10.1001/jama.284.20.2606

21. McClave AK, McKnight-Eily LR, Davis SP, Dube SR. Smoking characteristics of adults with selected lifetime mental illnesses: results from the 2007 National Health Interview Survey. Am J Public Health. 2010;100(12):24642472. doi:10.2105/AJPH.2009.188136

22. Williams JM, Ziedonis D. Addressing tobacco among individuals with a mental illness or an addiction. Addict Behav. 2004;29(6):1067-1083. doi:10.1016/j.addbeh.2004.03.009

CONFLICTS OF INTEREST

The authors have completed and submitted the ICMJE Form for Disclosure of Potential Conflicts of Interest and none was reported.

\section{FUNDING}

There was no source of funding for this research.

PROVENANCE AND PEER REVIEW

Not commissioned; externally peer reviewed. 